\title{
Review on Modelling Aspect of Ryanodine Receptor in CA1 Neuron
}

\author{
Sonupriya \\ Biomedical Engineering, \\ Government Engineering College, \\ Sector-28, Gandhinagar-382028, \\ Gujarat, India
}

\author{
Vijay Dave \\ Biomedical Engineering, \\ Government Engineering College, \\ Sector-28, Gandhinagar-382028, \\ Gujarat India
}

\begin{abstract}
Alzheimer is a neurodegenerative disease, which is most prevalent in worldwide. But there is no cure for it so far. From many reasons, elevated calcium concentration is one, that has their roles in this disease, and it starts at early stages. According to studies, Ryanodine receptor(RYR) can be targeted for further studies, for early detection of Alzheimer 's disease(AD) and for therapeutic drug for treatment, since alteration in intracellular calcium concentration caused by many channel, among them one of is increase in expression of RYR, which increases the calcium flux at intracellular level. Also based on calcium induced calcium release, it activates its neighbouring RYR as well. So there is up regulation in intracellular calcium concentration, which deteriorate memory process. In addition, it affects action potential(shape)by the activation of large conductance channel, since it plays vital role in neurotransmitter release. In later stage, apoptosis takes place (neuron cell death) which characterised by increase in memory loss, ( so neural connection decreases). Further, this Alzheimer starts in hippocampus, where there significantly reduction of neuronal density, especially in CA1 neurons. This occurs at an early stage of disease. In this paper we have explored the Ryanodine and their mechanism in neuron.
\end{abstract}

Keywords- Alzheimer, neurodegenerative disease, Calcium, Ryanodine receptor, calcium induced calcium release

\section{(I) INTRODUCTION}

Hippocampus plays a vital role in memory formation. Generally, Cornu ammonis (hippocampus proper) and dentate gyrus are the two parts of hippocampus. But, by some of the anatomist, hippocampus has divided into Hippocampus proper (Cornu ammonis), dentate gyrus, subiculum, and entorhinal cortex(EC) area. Hippocampus proper (Cornu ammonis) is further divided into CA1, CA2, CA3, and CA4 based on histology. In that, CA1 plays critical role in contextual and autobiographical memory retrieval, re-experiencing detailed episodic memories. It also responsible for Long term potentiation(LTP). CA1 contains pyramidal cell, which is named due to its shape, it mediate cognitive functions. So, CA1 is the region, plays role in new memory formation and strengthens the memory[1,2,3].

\section{(A)Alzheimer's Disease}

Alzheimer's Disease(AD) which is neurodegenerative, results in memory impairment and affecting mainly elderly people. This happens because neurons, which is responsible for cognitive function, gets damaged, so, it diminish cognition, memory, language, and is defined by presence of dementia [4]. The hallmark of the disease is defined by the presence of extracellular amyloid $\beta(\mathrm{A} \beta)$ plaques and intracellular neurofibrillary tangles (NFTs) containing hyper-phosphorylated tau, which in normal holds the microtubule protein together, acts as road for the transport of intracellular nutrient, however, in $\mathrm{AD}$ transportation of nutrients is blocked by NFT, and cell death occurs [5].

Hippocampus linked with memory formation, so the first degenerative process starts in hippocampus, under $\mathrm{AD}$, hippocampus begins shrinking(atrophy) [6]. Then degeneration proliferate all over the temporal associated cortex, parietal areas. As AD grows, frontal cortex gets affected. It cause profound damage on various component of limbic system [7,8]. In $\mathrm{AD}$, there is significant reduction in neuron at CA1, CA3 hippocampal area, however, as per the analysis, there is huge loss in CA1 neuron density, in comparison with other level[9].

At cellular level, Calcium ion being a second messenger, plays vital role in physiological functions[10], in brain, these are neurotransmitter release, action potential, memory formation [11]. So, fluctuation in calcium concentration beyond the required level, results in pathogenesis i.e neurodegenerative disease, Alzheimer 's disease[12], also perturbance in calcium concentration, occurs in advance of neuron cell death and cognitive decline in Alzheimer[13]. Further, in Alzheimer, ryanodine receptor(RYR) expression at intracellular level, rises with early cognitive decline and neurofibrillary pathology, and at late stage, it reduced in CA1-CA4, subiculum regions[14].

The calcium inside the cell is maintained and regulated by some channels located on plasma membrane, endoplasmic reticulum and mitochondria. Here, in neuron, rise in calcium level results in neurotransmitter release at synaptic cleft, that contributes towards synaptic plasticity as well as action potential[15,16]. Endoplasmic calcium at dendrites plays roles in post synaptic process and synaptic plasticity[17] and at axon in neurotransmitter release[18]. Calcium concentration is maintained at different level like $2 \mathrm{mM}$ in extracellular space, cytosolic is 100nM[19]. Variation in intracellular calcium concentration underlies cellular mechanism of learning and memory(synaptic plasticity), include Long term potentiation(LTP) and long 
term depression(LTD). High calcium concentration spike triggers LTP, in that during certain phase of sleep, information consolidate to permanent memory from temporary memory. Small rise in calcium activate Long term depression(LTD) during another phase of sleep, that erases temporary memory. While in $\mathrm{AD}$, permanent rise in calcium erases temporary memory, before it can be transferred to permanent memory[20]. So, change in the level of intracellular calcium get involved in brain activity, including learning and memory and memory loss precedes the massive cell loss[21].

\section{(II) LITERATURE SURVEY}

In Fig.1:(A), in response of , neurotransmitter releases from presynaptic axon terminal, influx of calcium takes place from voltage gated calcium channel(VGCC) at post synaptic terminal, during depolarization[22,23]. Then calcium interact with RYR, caused it to get open, efflux of calcium from endoplasmic reticulum takes through this channel[24].

The second major intracellular calcium channel is Ionsitol triphosphate(IP3), is ligand gated IP3 channel. External stimuli acts on G-protein, which activates phospholipase $\mathrm{C}$, and generate IP3, IP3 diffuse from plasma membrane to endoplasmic reticulum, binds to and opens ligand gated ion channel, Calcium moves out from the endoplasmic reticulum into the cytosol, which stores calcium, and it activates various cellular function. However, mitochondria takes up the calcium using mitochondria calcium uniportar (MCU). Sodium/calcium exchange(NCX) moves the calcium out of cytoplam[25].

There is other calcium influx pathway, SOCC(store operated calcium channel), which activated when ER calcium depleted. In that STIM which sits in the ER membrane, forms clusters, closure to the plasma membrane, interacts with Orai, forms a calcium channel to allow calcium influx from extracellular medium. Also, depleted ER calcium store, refilled by sarco/endoplasmic reticulum ATPase pump(SERCA) pump[25].

(A)

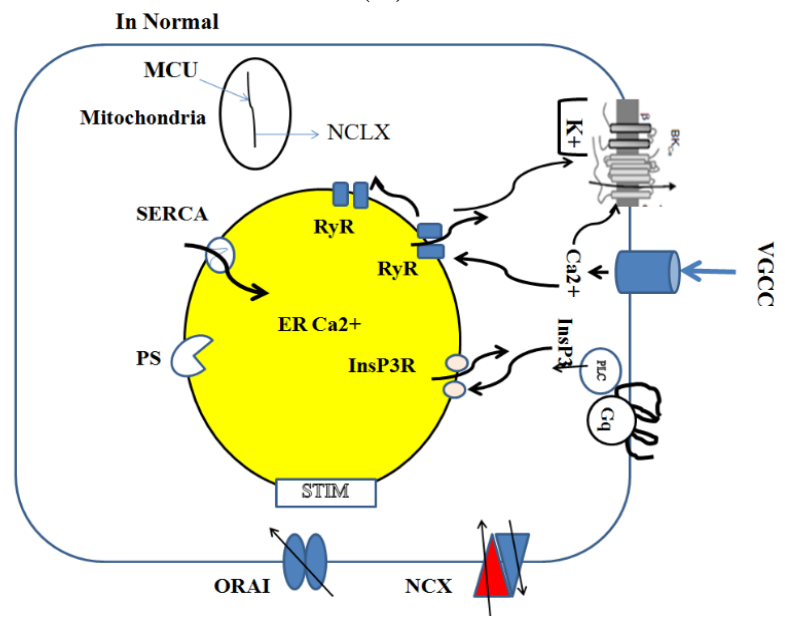

Fig 1:(A) intracellular mechanism in normal neuron
Then increase in level of intracellular calcium ,during action potential depolarization led to activation of calcium activated potassium channel, situated near VGCC[26]. Ultimately, efflux of potassium ion and closure of calcium channel takes place and it produce after fast hyperpolarisation[27]. So, it contributes in maintenance of shape and duration of action potential [28].

(B)

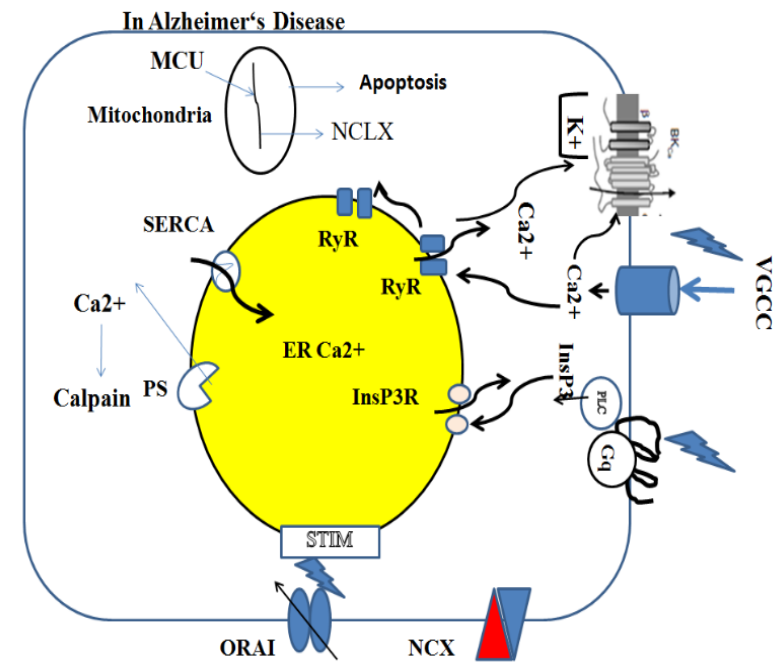

Fig.1(b) intracellular mechanism in Alzheimer

It is important to have proper balance in calcium haemostasis, for neuronal survival and memory formation(synaptic plasticity). However, In AD, in fig.1(b) there is increase in VGCC, by which calcium influx rises[29]. Ryanodine also works with increase in its expression[30,31,32] Presenilin acts as leak channel [33] and it also alters the normal function of SERCA[34]. Also, gating of IP3 increases, due to interaction of Presenilin with IP3 receptor[35] and stimulation of mGluR receptor linked with IP3 production[36]. In addition depletion of Endoplasmic reticulum calcium, activates Store operated calcium entry via the STIM/ ORAI pathway[37]. And efflux of accumulated intracellular calcium level via Sodium/ calcium exchange(NCX) gets inhibited in Alzheimer condition[38]. Increase calcium cause excessive flux into the mitochondria that increases its overload, generation of superoxide radicals, caspases and cytochrome $\mathrm{C}$, that led to cell death(Apoptosis) [34].

In addition, raised intracellular calcium level affects LTP[34] and Action Hyperpolarisation, which are result of calcium activated potassium channel[39]. Also, increased calcium level, increased activity of calpain, which in turn led to Tau hyperphosphorylation[40]. So all might ultimately contributes towards later stages of disease, that is cell loss. So under AD, malfunctioning of these channel, results in increased intracellular calcium level and it has deleterious effects on the functioning of cell.

Membrane permeability to potassium ion, which is vital for neurotransmitter release and many other cellular function is controlled by intracellular calcium[41]. In hippocampal 
pyramidal neuron, ryanodine receptor are present at higher level, which is activated through calcium influx from VGCC, followed by calcium induced calcium release(CICR), which dominate in CA1 neuron for ryanodine receptor[42], so there is link between AHP and calcium release from Ryanodine receptor. Also, Ryanodine receptor on stimulation, enhance memory process [43] and on blockade RYR, in mouse model it reduce memory impairment[44], however, it induce amnesia[45].

\section{(III) MATHEMATICAL FORMULATION AND ANALYSIS}

Here, the author has conduct research on RYR in cardiac myocytes, to find RYR adaptation. With increase in calcium concentration, open probability of ryanodine channel increases.

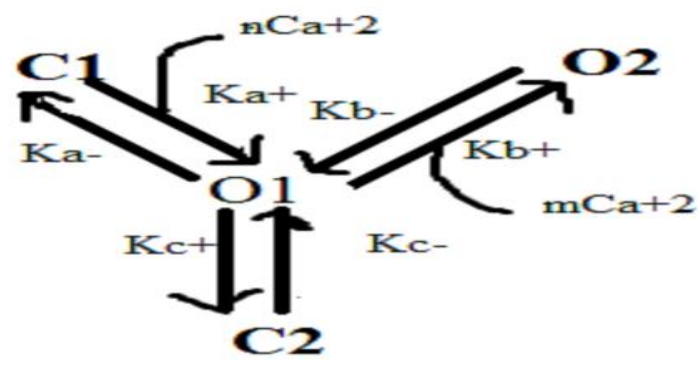

Fig 2 transition among four state of RYR. step a and b is only calcium dependent[46].

In fig. $2 \mathrm{C} 1$ and $\mathrm{C} 2$ are two closed state, where as $\mathrm{O} 1$ and $\mathrm{O} 2$ are open state. At low calcium concentration it is $\mathrm{C} 1$ states. In transition state, state $\mathrm{C} 1$ to $\mathrm{O} 1$ and $\mathrm{O} 1$ to $\mathrm{O} 2$ are calcium dependent, which depends on binding of $\mathrm{n}$ and $\mathrm{m}$ calcium ion respectively. The step in the absence of $\mathrm{O} 1$ to $\mathrm{C} 2$ are considered to be CICR. On slow transition from $\mathrm{O} 1$ to $\mathrm{C} 2$ it exhibits inactivation. when we translate the schematic diagram into kinetic equation using mass action law then differential equation can be written as follows :-

$\frac{\mathrm{dPc} 1}{\mathrm{dt}}=-\mathrm{Ka}^{+}\left[\mathrm{Ca}^{2}\right]^{\mathrm{n}} \mathrm{Pc} 1+\mathrm{Ka}^{-} \mathrm{Po} 1$

$\frac{\mathrm{dPo} 1}{\mathrm{dt}}=\mathrm{Ka}^{+}\left[\mathrm{Ca}^{2}\right]^{\mathrm{n}} \mathrm{Pc} 1-\mathrm{Ka}^{-} \mathrm{Po} 1-\mathrm{Kb}^{+}\left[\mathrm{Ca}^{2}\right]^{\mathrm{m}} \mathrm{Po} 1+$

$\mathrm{Kb}^{-} \mathrm{Po} 2-\mathrm{Kc}^{+} \mathrm{Po} 1+\mathrm{Kc}^{-} \mathrm{Pc} 2$

$\frac{\mathrm{dPo} 2}{\mathrm{dt}}=\mathrm{Kb}^{+}\left[\mathrm{Ca}^{2+}\right]^{\mathrm{m}} \mathrm{Po} 1-\mathrm{Kb}^{-} \mathrm{Po} 2$

$\frac{\mathrm{dPc} 2}{\mathrm{dt}}=\mathrm{Kc}^{+} \mathrm{Po} 1-\mathrm{Kc}^{-} \mathrm{Pc} 2$

O2 states corresponds to plateau open probability increasing. $\mathrm{Ki}-^{+}$are rate constant, $\mathrm{a} \& \mathrm{~b}$ is fast(millisecond time scale and $\mathrm{C}$ is slow (second time scale. P C1 is RYR fraction that is state in $\mathrm{C} 1$. From $\frac{\mathrm{dPc}}{\mathrm{dt}}$, we can deduce that how this vary with time.

The equation for Ppeak open probability is given by[46] Ppeak $\left.\left.\left(\left[\mathrm{Ca}^{2+}\right]\right)=\left(\operatorname{Winf}(0.1 \mu \mathrm{M})+\left(\left[\mathrm{Ca}^{2+}\right]\right) / \mathrm{Kb}\right)^{\wedge} 3\right)\right) /$ $\left(1+\left(\mathrm{Ka} /\left[\mathrm{Ca}^{2+}\right\}\right)^{\wedge} 4+\left(\left[\mathrm{Ca}^{2}{ }^{+}\right] / \mathrm{Kb}\right)^{\wedge} 3\right)$ where $\operatorname{Winf}(0.1 \mu \mathrm{M})$ is the equilibrium value of $1-\mathrm{Pc} 2$ evaluated at the initial value $\left[\mathrm{Ca}^{\wedge} 2+\right]=0.1 \mu \mathrm{M}$

Plateau value of Po is equilibrium value of $\mathrm{Po} 1+\mathrm{Po} 2$ and it can also be written as Popen. So, Open Probability(Popen) of Ryanodine receptor (normal) from Keizer and Levine is given by[46]

$$
\text { Popen }=\mathrm{W}\left(\left(1+\left(\frac{\mathrm{C}}{\mathrm{Kb}}\right)^{3}\right) /\left(\left(1+\left(\frac{\mathrm{Ka}}{\mathrm{C}}\right)^{4}+\left(\frac{\mathrm{C}}{\mathrm{Kb}}\right)^{3}\right)\right.\right.
$$

where $\mathrm{W}=1-\mathrm{C} 2$, fraction of channel not in state $\mathrm{C} 2, \mathrm{Ka}$ and $\mathrm{Kb}$ are kinetic parameter. $\mathrm{W}$ determine the rate of relaxation to its plateau[47].

$$
\text { Jryr }=\text { Vryr } \times \text { Popen } \times(S-C)
$$

The driving force for the flux is Endoplasmic Reticulum membrane calcium gradient is (S-C) [47] Herein , AD, open probability of ryanodine receptor increases. In the absence of external calcium fluxes (closed cell model) the mechanism led to bistability.

kinetic model of Ryanodine receptor is used to describe CICR from internal store. This is combined with a passive leak and SERCA pump that returns calcium to the store[46].

$$
\frac{\mathrm{dc}}{\mathrm{dt}}=(\mathrm{V} 1 \cdot \text { Popen }+\mathrm{V} 2)(\mathrm{S}-\mathrm{C})-\left(\mathrm{V} 3 *\left(\frac{\mathrm{C}^{2}}{\mathrm{C}^{2}+\mathrm{K}^{2}}\right)\right.
$$

Table:1Simulation parameter

\begin{tabular}{|l|l|l|}
\hline Property & Value & Reference \\
\hline Kinetic parameter,Ka & $0.372 \mu \mathrm{M}$ & 47 \\
\hline Kinetic parameter, $\mathrm{Kb}$ & $0.0 .636 \mu \mathrm{M}$ & 47 \\
\hline Kc,kinetic parameter & .0571 & 47 \\
\hline $\mathrm{Vryr}$ & $10^{-6} \mathrm{~cm} / \mathrm{ms}$ & 47 \\
\hline $\begin{array}{l}\text { C(calcium in } \\
\text { concentration } \\
\text { cytosol) }\end{array}$ & 0.1 to $0.9 \mu \mathrm{M}$ & 46 \\
\hline $\begin{array}{l}\text { S(calcium } \\
\text { concentration in ER }\end{array}$ & $250 \mu \mathrm{M}$ & 49 \\
\hline
\end{tabular}

Table:2 Parameters for closed cell

\begin{tabular}{|l|l|l|l|}
\hline Parameter & Value & Meaning & Reference \\
\hline V1 & $40 \mathrm{~s}-1$ & $\begin{array}{l}\text { Rate constant for } \\
\text { RYR }\end{array}$ & $(47)$ \\
\hline V2 & $0.5 \mathrm{~s}-1$ & $\begin{array}{l}\text { Rate constant for } \\
\text { store leak }\end{array}$ & $(47)$ \\
\hline V3 & $1000 \mu \mathrm{Ms}-1$ & $\begin{array}{l}\text { Maximal rate of } \\
\text { SERCA Pump }\end{array}$ & $(47)$ \\
\hline K3 & $0.30 \mu \mathrm{M}$ & $\begin{array}{l}\text { Dissociation for } \\
\text { constant for } \\
\text { SERCA }\end{array}$ & $(47)$ \\
\hline
\end{tabular}



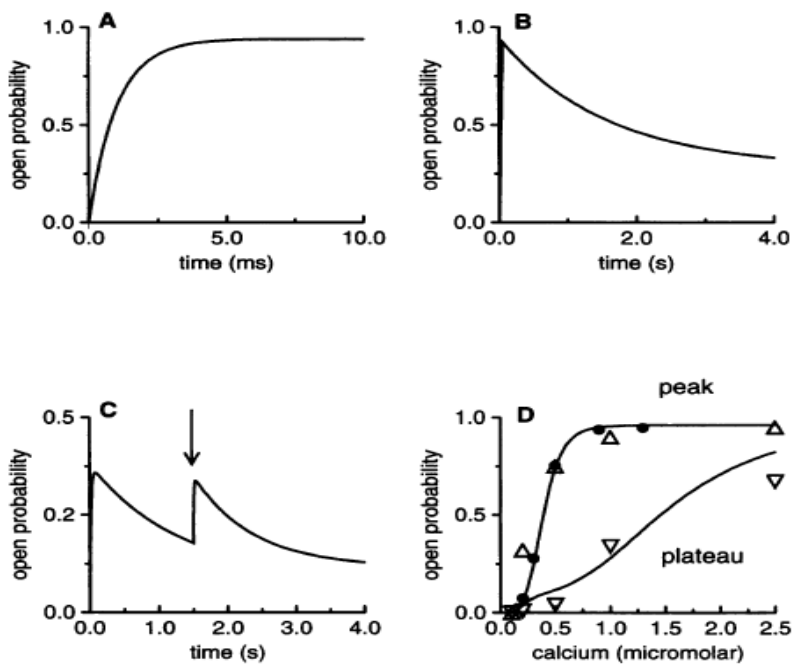

Fig.3 Variation in Ryanodine open probalitywith time and calcium[46]

Fig. $3 \mathrm{~A}$ is $\mathrm{Po}=\mathrm{Po} 1+\mathrm{Po} 2$, where calcium vary from 0.1 to $0.9 \mu \mathrm{M}$. activation takes place in miliseconds while decline to plateau in seconds In fig. 3B is inactivation is there, with time scale in seconds.Fig. 3C, here first variation in calcium ions occurs from 0.1 to 0.35 at $\mathrm{t}=0$ followed by enhancement up to $0.50 \mu \mathrm{M}$. Fig. 3D the peak and plateau that depends on calcium, solid curves is theoritical value like that in fig,3Awhere $\triangle$ as is experimental data, upward facing triangle is peak and downward is plateau[46].

Another RYR model with no time dependence or gating kinetics was constructed by Friel(1995). This calcium model is based on calcium oscillation in sympathetic neurons[48].

Here, flux is proportional to concentration difference

$$
\text { Jryr }=\mathrm{K} 3(\mathrm{Ce}-\mathrm{C})
$$

where $\mathrm{Ce}$ and $\mathrm{C}$ are $\mathrm{ER}$ calcium concentration and cytoplasmic calcium concentration respectively. And

$$
\mathrm{K} 3=\mathrm{k} 1+\left(\frac{\mathrm{K} 2 \mathrm{C}^{\mathrm{n}}}{\left(\mathrm{Kd}^{\mathrm{n}}+\mathrm{C}^{\mathrm{n}}\right)}\right)
$$

where $\mathrm{n}=3$, the first factor $\mathrm{K} 3$ is open probability, where $\mathrm{K} 1, \mathrm{~K} 2$ and $\mathrm{Kd}$ are parameters. The parameter $\mathrm{K} 1$ is the zero calcium concentration level leak. Kd corresponds to RYR channel sensitivity for Calcium induced calcium release (CICR), and $\mathrm{K} 2$ is the maximal rate of channel[48].

$$
\begin{aligned}
\mathrm{K} 1 & =0.013 s^{-1}, \\
\mathrm{Kd} & =0.13 \mu \mathrm{M} \quad \mathrm{K} 2=0.18 s^{-1}
\end{aligned}
$$

\section{(IV) CONCLUSION AND FUTURE SCOPE}

This review paper attempts to explain, what generally happens at intracellular calcium signalling in Alzheimer. In $\mathrm{AD}$, there is up regulation in calcium at intracellular level by internal stores and extracellular mechanism. Among them, this review focused on Ryanodine receptor, in which there is increase in expression of ryanodine receptor, that is open probability of ryr increases. In addition, Ryr involves in memory process, and calcium released via this channel takes part in action potential. So, in future, model will be focus on Ryr open probability and from them we can drive flux and current.

\section{REFERENCE}

[1] Last, R. J. (1999). Hippocampal anantomy.

[2] Anand, K. S., \& Dhikav, V. (2012). Hippocampus in health and disease: An overview. Annals of Indian Academy of Neurology, 15(4), 239.

[3] Bartsch, T., Döhring, J., Rohr, A., Jansen, O., \& Deuschl, G. (2011). CA1 neurons in the human hippocampus are critical for autobiographical memory, mental time travel, and autonoetic consciousness. Proceedings of the National Academy of Sciences, 108(42), 17562-17567.

[4] 4)Alzheimer's Association. (2017). 2017 Alzheimer's disease facts and figures. Alzheimer's \& Dementia, 13(4), 325-373.

[5] Querfurth, H. W., \& LaFerla, F. M. (2010). Mechanisms of disease. $N$ Engl J Med, 362(4), 329-344.

[6] Van de Pol, L. A., Hensel, A., Barkhof, F., Gertz, H. J., Scheltens, P., \& Van Der Flier, W. M. (2006). Hippocampal atrophy in Alzheimer disease: age matters. Neurology, 66(2), 236-238.

[7] Bozoki, A. C., Korolev, I. O., Davis, N. C., Hoisington, L. A., \& Berger, K. L. (2012). Disruption of limbic white matter pathways in mild cognitive impairment and Alzheimer's disease: A DTI/FDG-PET Study. Human brain mapping, 33(8), 1792-180

[8] Holtzman, D. M., Morris, J. C., \& Goate, A. M. (2011). Alzheimer's disease: the challenge of the second century. Science translational medicine, 3(77), 77sr1-77sr1

[9] Padurariu, M., Ciobica, A., Mavroudis, I., Fotiou, D., \& Baloyannis, S. (2012). Hippocampal neuronal loss in the CA1 and CA3 areas of Alzheimer's disease patients. Psychiatria Danubina, 24(2.), 152-158

[10] Clapham, D. E. (2007). Calcium signaling. Cell, 131(6), 10471058.

[11] Berridge, M. J. (1998). Neuronal calcium signaling. Neuron, 21(1), 13-26.

[12] Verkhratsky, A., Mattson, M. P., \& Toescu, E. C. (2004). Aging in the mind. Trends in neurosciences, 27(10), 577-578.

[13] Supnet, C., \& Bezprozvanny, I. (2010). The dysregulation of intracellular calcium in Alzheimer disease. Cell calcium, 47(2), 183-189.

[14] Kelliher, M., Fastbom, J., Cowburn, R. F., Bonkale, W., Ohm, T. G., Ravid, R., ... \& O'Neill, C. (1999). Alterations in the ryanodine receptor calcium release channel correlate with Alzheimer's disease neurofibrillary and $\beta$-amyloid pathologies. Neuroscience, 92(2), 499-513.

[15] Berridge, M. J., Bootman, M. D., \& Lipp, P. (1998). Calcium-a life and death signal. Nature, 395(6703), 645.

[16] Sandler, V. M., \& Barbara, J. G. (1999). Calcium-induced calcium release contributes to action potential-evoked calcium transients in hippocampal CA1 pyramidal neurons. Journal of Neuroscience, 19(11), 4325-4336.

[17] Holbro, N., Grunditz, ̊., \& Oertner, T. G. (2009). Differential distribution of endoplasmic reticulum controls metabotropic signaling and plasticity at hippocampal synapses. Proceedings of the National Academy of Scienc es, 106(35), 15055-15060.

[18] Emptage, N. J., Reid, C. A., \& Fine, A. (2001). Calcium stores in hippocampal synaptic boutons mediate short-term plasticity, store-operated $\mathrm{Ca} 2+$ entry, and spontaneous transmitter release. Neuron, 29(1), 197-208.

[19] Meldolesi, J., \& Pozzan, T. (1998). The endoplasmic reticulum $\mathrm{Ca} 2+$ store: a view from the lumen. Trends in biochemical sciences, 23(1), 10-14

[20] Berridge, M. J. (2010). Calcium hypothesis of Alzheimer's disease. Pflügers Archiv-European Journal of Physiology, 459(3), 441-449.

[21] Jacobsen, J. S., Wu, C. C., Redwine, J. M., Comery, T. A., Arias, R., Bowlby, M., ... \& Bloom, F. E. (2006). Early-onset behavioral and synaptic deficits in a mouse model of Alzheimer's disease. Proceedings of the National Academy of Sciences, 103(13), 5161-5166. 
[22] Holbro, N., Grunditz, A., \& Oertner, T. G. (2009). Differential distribution of endoplasmic reticulum controls metabotropic signaling and plasticity at hippocampal synapses. Proceedings of the National Academy of Sciences, 106(35), 15055-15060.

[23] Emptage, N. J., Reid, C. A., \& Fine, A. (2001). Calcium stores in hippocampal synaptic boutons mediate short-term plasticity, store-operated $\mathrm{Ca} 2+$ entry, and spontaneous transmitter release. Neuron, 29(1), 197-208.

[24] Futagi, D., \& Kitano, K. (2015). Ryanodine-receptor-driven intracellular calcium dynamics underlying spatial association of synaptic plasticity. Journal of computational neuroscience, 39(3), 329-347.

[25] Dupont, G., Falcke, M., Kirk, V., \& Sneyd, J. (2016). Models of calcium signalling (Vol. 43). Springer.

[26] Chavis, P., Ango, F., Michel, J. M., Bockaert, J., \& Fagni, L. (1998). Modulation of big $\mathrm{K}+$ channel activity by ryanodine receptors and L-type $\mathrm{Ca} 2+$ channels in neurons. European Journal of Neuroscience, 10(7), 2322-2327.

[27] Bond, C. T., Herson, P. S., Strassmaier, T., Hammond, R., Stackman, R., Maylie, J., \& Adelman, J. P. (2004). Small conductance $\mathrm{Ca} 2+-$ activated $\mathrm{K}+$ channel knock-out mice reveal the identity of calcium-dependent afterhyperpolarization currents. Journal of Neuroscience, 24(23), 5301-5306.

[28] Robitaille, R., \& Charlton, M. P. (1992). Presynaptic calcium signals and transmitter release are modulated by calciumactivated potassium channels. Journal of Neuroscience, 12(1), 297-305.

[29] Coon, A. L., Wallace, D. R., Mactutus, C. F., \& Booze, R. M. (1999). L-type calcium channels in the hippocampus and cerebellum of Alzheimer's disease brain tissue. Neurobiology of aging, 20(6), 597-603

[30] Stutzmann, G. E., Smith, I., Caccamo, A., Oddo, S., LaFerla, F. M., \& Parker, I. (2006). Enhanced ryanodine receptor recruitment contributes to $\mathrm{Ca} 2+$ disruptions in young, adult, and aged Alzheimer's disease mice. Journal of Neuroscience, 26(19), 5180-5189.

[31] Supnet, C., Grant, J., Westaway, D., \& Mayne, M. (2006). Amyloid- $\beta-(1-42)$ increases ryanodine receptor-3 expression and function in neurons of TgCRND8 mice. Journal of Biological Chemistry, 281(50), 38440-38447.

[32] Chan, S. L., Mayne, M., Holden, C. P., Geiger, J. D., \& Mattson, M. P. (2000). Presenilin-1 mutations increase levels of ryanodine receptors and calcium release in $\mathrm{PC} 12$ cells and cortical neurons. Journal of Biological Chemistry, 275(24), 18195-18200.

[33] Tu, H., Nelson, O., Bezprozvanny, A., Wang, Z., Lee, S. F., Hao, Y. H., ... \& Bezprozvanny, I. (2006). Presenilins form ER Ca2+ leak channels, a function disrupted by familial Alzheimer's disease-linked mutations. Cell, 126(5), 981-993.

[34] Berridge, M. J. (2011). Calcium signalling and Alzheimer's disease. Neurochemical research, 36(7), 1149-1156.

[35] Cheung, K. H., Shineman, D., Müller, M., Cardenas, C., Mei, L., Yang, J., ... \& Foskett, J. K. (2008). Mechanism of Ca2+ disruption in Alzheimer's disease by presenilin regulation of InsP3 receptor channel gating. Neuron, 58(6), 871-883.

[36] Demuro, A., \& Parker, I. (2013). Cytotoxicity of intracellular $\mathrm{a} \beta 42$ amyloid oligomers involves $\mathrm{Ca} 2+$ release from the endoplasmic reticulum by stimulated production of inositol trisphosphate. Journal of Neuroscience, 33(9), 3824-3833.

[37] Leissring, M. A., Akbari, Y., Fanger, C. M., Cahalan, M. D., Mattson, M. P., \& LaFerla, F. M. (2000). Capacitative calcium entry deficits and elevated luminal calcium content in mutant presenilin-1 knockin mice. The Journal of cell biology, 149(4), 793-798

[38] Wu, A., Derrico, C. A., Hatem, L., \& Colvin, R. A. (1997). Alzheimer's amyloid-beta peptide inhibits sodium/calcium exchange measured in rat and human brain plasma membrane vesicles. Neuroscience, 80(3), 675-684

[39] Lee, U. S., \& Cui, J. (2010). BK channel activation: structural and functional insights. Trends in neurosciences, 33(9), 415-423.

[40] Kurbatskaya, K., Phillips, E. C., Croft, C. L., Dentoni, G. Hughes, M. M., Wade, M. A., ... \& Hanger, D. P. (2016) Upregulation of calpain activity precedes tau phosphorylation and loss of synaptic proteins in Alzheimer's disease brain. Acta neuropathologica communications, 4(1), 34.

[41] Lee, U. S., \& Cui, J. (2010). BK channel activation: structural and functional insights. Trends in neurosciences, 33(9), 415-423.

[42] Sterratt, D., Graham, B., Gillies, A., \& Willshaw, D. (2011). Principles of computational modelling in neuroscience. Cambridge University Press.

[43] Galeotti, N., Quattrone, A., Vivoli, E., Norcini, M., Bartolini, A. \& Ghelardini, C. (2008). Different involvement of type 1, 2, and 3 ryanodine receptors in memory processes. Learning \& memory, 15(5), 315-323.

[44] Oulès, B., Del Prete, D., Greco, B., Zhang, X., Lauritzen, I., Sevalle, J., ... \& Benfenati, F. (2012). Ryanodine receptor blockade reduces amyloid- $\beta$ load and memory impairments in Tg2576 mouse model of Alzheimer disease. Journal of Neuroscience, 32(34), 11820-11834.

[45] Popugaeva, E., \& Bezprozvanny, I. (2013). Role of endoplasmic reticulum $\mathrm{Ca} 2+$ signaling in the pathogenesis of Alzheimer disease. Frontiers in molecular neuroscience, 6, 29

[46] Keizer, J., \& Levine, L. (1996). Ryanodine receptor adaptation and $\mathrm{Ca} 2+(-)$ induced $\mathrm{Ca} 2+$ release-dependent $\mathrm{Ca} 2+$ oscillations. Biophysical journal, 71(6), 3477-3487.

[47] Gabbiani, F., \& Cox, S. J. (2017). Mathematics for neuroscientists. Academic Press.

[48] Latulippe, J., Lotito, D., \& Murby, D. (2018). A mathematical model for the effects of amyloid beta on intracellular calcium. PloS one, 13(8), e0202503.

[49] Breit, M., Kessler, M., Stepniewski, M., Vlachos, A., \& Queisser, G. (2018). Spine-to-Dendrite Calcium Modeling Discloses Relevance for Precise Positioning of Ryanodine ReceptorContaining Spine Endoplasmic Reticulum. Scientific reports, $8(1), 1-17$ 